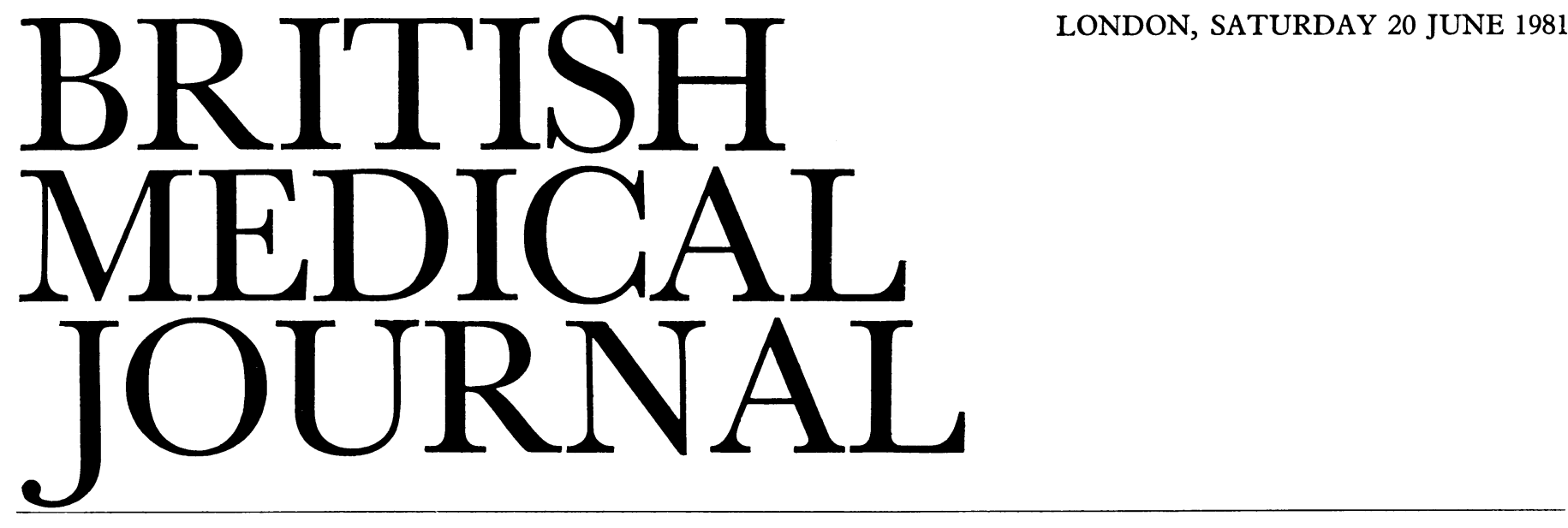

\title{
New evidence linking salt and hypertension
}

A relation between sodium and hypertension has been suspected since $2000 \mathrm{BC}$, when Huang $\mathrm{Ti}^{1}$ wrote: "Hence if too much salt is used in food the pulse hardens...." Sodium retention is known to be linked with secondary hypertension in conditions like Cushing's and Conn's syndromes. The controversy over salt and essential hypertension made little headway, however, until some recent studies on sodium handling in cells provided a new insight into possible mechanisms.

Essential hypertension is seen by some workers as the result purely of environmental influences and by others as a genetically determined disease. The most likely explanation is a combination of both, with a genetically predisposed individual being particularly susceptible to environmental influences. Numerous studies ${ }^{2}$ in different communities have shown a positive correlation between blood pressure and salt intake, but variations in other dietary constituents ${ }^{3}$ may be important, as well as socioeconomic factors. ${ }^{4}$ Furthermore, within any one community attempts to show a correlation between blood pressure and individual salt intake have usually been inconclusive, ${ }^{5}$ largely owing to the difficulty of accurately measuring dietary salt.

Experiments on the inbreeding of rats have produced a genetically predisposed group particularly sensitive to dietary salt. Dahl and colleagues ${ }^{6}$ were able to develop two distinct strains of rats, one of which always remained normotensive despite a high salt diet (salt resistant), and another which always became hypertensive on a high salt diet (salt sensitive). Transplantation and parabiosis experiments ${ }^{7-9}$ showed that the genetic fault lay in the kidney of the salt-sensitive animal, rendering it less able to excrete sodium, and that hypertension was mediated by a factor carried in the blood of the saltsensitive strain. This led to the suggestion ${ }^{10}$ that the hypertensive rats were in a state of expanded extracellular volume caused by the kidney's tendency to retain sodium but compensated by a circulating substance which promoted sodium excretion and also caused hypertension. This was supported by the finding ${ }^{11}$ that salt-sensitive rats excreted a sodium load at a higher rate than did the salt-resistant animals.

Human research has provided strong evidence for a similar mechanism in essential hypertension. de Wardener and his colleagues $^{12}$ have extracted a substance from human urine which, when injected intravenously, causes a transient natriuresis. Hypertensive patients also have an accelerated natriuresis when given a sodium load. ${ }^{13}$ An abnormality of sodium transport has recently been found ${ }^{14}$ in the erythrocytes of patients with essential hypertension and, more important, the same abnormality has been found in some of their normotensive relatives. ${ }^{15} 16$ This abnormality may, indeed, represent a genetic marker for essential hypertension inherited as a i single dominant gene. ${ }^{17}$ Leucocytes from hypertensive patients have been found to have a depressed sodium pump activity, ${ }^{18} \mathrm{~N}$ thought to be caused by a circulating inhibitor of sodium $\stackrel{\infty}{-}$ transport since plasma from hypertensive patients will suppress $\vec{\varphi}$ the sodium pump when incubated with cells from normoten- $\stackrel{\mathscr{\omega}}{\omega}$ sive people. ${ }^{19}$ Such an abnormality would be expected to lead $ᄋ$ to a high intracellular sodium concentration, and this has $N$ indeed been found in cells from hypertensive patients. ${ }^{18}$ c Blaustein ${ }^{20}$ suggests that the tendency to retain sodium, particularly in vascular cells, leads to a high intracellular $\vec{\bullet}$ calcium concentration, which in turn causes a rise in vascular $œ$ tone and hence a rise in peripheral resistance-and in this context it is of interest that the calcium antagonist nifedipine has been shown to have hypotensive properties. ${ }^{21}$

At this stage, therefore, an abnormality has been found, detectable in the laboratory, which may identify those people who have a genetic susceptibility to hypertension induced by a high salt intake. Before this hypothesis can be accepted several questions need to be answered. If susceptibility to essential hypertension is inherited as a single dominant gene why do we not find a bimodal distribution within a given population? Perhaps this reflects a highly variable salt intake within a bimodally susceptible population. This question deserves re-examination using modern statistical and epidemiological techniques. And does the laboratory abnormality actually detect future hypertensive patients, and are they "salt sensitive?" If the answers are Yes an important advance will be 9 possible in preventive medicine.

${ }^{1}$ Veith I. Huang Ti Nei Ching Su Wen. The Yellow Emperor's classic of internal medicine. Berkeley: University of California Press, 1973.

${ }^{2}$ Freis ED. Salt, volume and the prevention of hypertension. Circulation 1976;53:589-95.

${ }^{3}$ Meneely GR, Ball COT, Youmans JB. Chronic sodium chloride toxicity : the protective effect of added potassium chloride. Ann Intern Med 1957; 47:263-73.

4 Scotch NA. A preliminary report on the relation of sociocultural factors to hypertension among the Zulu. Ann NY Acad Sci 1960;84:1000-9.

5 Swales JD. Dietary salt and hypertension. Lancet $1980 ; 1: 1177-9$.

${ }^{6}$ Dahl LK, Schackow E. Effects of chronic excess salt ingestion: experimental hypertension in the rat. Can Med Assoc f 1964;90:155-60.

7 Bianchi G, Fox V, Di Francesco GF, Giovannetti AM, Pagetti D. Blood $\overrightarrow{\mathbb{D}}$ pressure changes produced by kidney cross-transplantation between spontaneously hypertensive rats and normotensive rats. Clin Sci Mol Med $1974 ; 47: 435-48$.

${ }^{8}$ Dahl LK, Heine M, Thompson $\mathrm{K}$. Genetic influence of the kidney on blood pressure. Evidence from chronic renal homografts in rats of opposite predispositions to hypertension. Circ Res 1974 ;34:94-101.

${ }^{9}$ Dahl LK, Knudsen KD, Heine M, Leitl G. Effects of chronic excess salt 
ingestion: genetic influences on the development of salt hypertension in parabiotic rats: evidence for a humoral factor. $\mathcal{F} \operatorname{Exp}$ Med $1967 ; 126$ 687-99.

10 Bianchi G, Baer PG, Fox U, Duzzi L, Pagetti D, Giovanetti AM. Changes in renin, water balance, and sodium balance during development of high blood pressure in genetically hypertensive rats. Circ Res $1975 ; 36 / 37$, suppl:1-153-61.

11 Ben-Ishay D, Knudsen KD, Dahl LK. Exaggerated response to isotonic saline loading in genetically hypertension-prone rats. $f$ Lab Clin Med $1973 ; 82: 597-604$

12 Clarkson EM, Raw SM, de Wardener HE. Further observations on a lowmolecular-weight natriuretic substance in the urine of normal man. Kidney Int 1979;16:710-21.

${ }^{13}$ Baldwin DS, Biggs AW, Goldring W, Hulet WH, Chasis H. Exaggerated natriuresis in essential hypertension. $A m \mathcal{F}$ Med $1958 ; 24: 893-902$.

14 Garay RP, Meyer P. A new test showing abnormal $\mathrm{Na}^{+}$and $\mathrm{K}^{+}$fluxes in erythrocytes of essential hypertensive patients. Lancet $1979 ; \mathrm{i}: 349-53$.

15 Garay RP, Dagher G, Pernollet MP, Devynck MA, Meyer P. Inherited defect in a $\mathrm{Na}^{+}, \mathrm{K}^{+}$-co-transport system in erythrocytes from essential hypertensive patients. Nature $1980 ; 284: 281-3$.

16 Woods KL, Beevers DG, West M. Familial abnormality of erythrocyte cation transport in essential hypertension. $\mathrm{Br} M e d \mathcal{F} 1981$;282:1186-8.

${ }^{17}$ Meyer P, Garay RP, Nazaret C, et al. Inheritance of abnormal erythrocyte cation transport in essential hypertension. Br Med F 1981 ;282:1114-7.

18 Edmondson RPS, Thomas RD, Hilton PJ, Patrick J, Jones NF. Abnorma leucocyte composition and sodium transport in essential hypertension. Lancet 1975 ; : $1003-5$.

10 Poston L, Sewell RB, Wilkinson SP, et al. Evidence for a circulating sodium transport inhibitor in essential hypertension. $\mathrm{Br}$ Med $\mathcal{f} 1981$; 282:847-9.

${ }^{20}$ Blaustein MP. Sodium ions, calcium ions, blood pressure regulation, and hypertension: a reassessment and a hypothesis. Am $\mathcal{f}$ Physiol 1977 232:c165-73.

${ }^{21}$ Guazzi M, Olivari MT, Polese A, Fiorentini C, Magrini F, Moruzzi P. Nifedipine, a new antihypertensive with rapid action. Clin Pharmacol Ther $1977 ; 22: 528-32$

\section{Monteggia fractures}

Monteggia described the injury complex named after him in 1814: a fracture of the proximal third of the shaft of the ulna, with dislocation of the radial head from both the superior radioulnar and the radiohumeral joints. The radial head may come to lie either anteriorly or posteriorly. Though rare, the fracture occurs in both adults and children and is sometimes associated with fractures around the wrist. ${ }^{1}$

The fracture has a justifiably bad reputation and gives rise to both diagnostic and therapeutic problems. Over 100 years passed after Monteggia's description before these were solved. The results of faulty management are appalling. WatsonJones $^{2}$ reviewed 34 Monteggia fracture-dislocations treated by many surgeons and found that 32 patients had serious permanent disabilities.

The improvement in the management of Monteggia fractures has come from internal fixation but the first requirement is early accurate diagnosis. This is not as simple as might be thought, for the first $x$-ray film may show the ulnar fracture with the radial head normally located. Subsequent films may show that the radial head has become displaced. If the follow-up radiograph is omitted the fracture will heal with the radial head in the dislocated position. All patients who have a fracture of the proximal third of the ulna must, therefore, be assumed to have a Monteggia fracture until later $x$-ray films prove that the radial head is stable and remains correctly located throughout healing.

The fracture occurs in two ways. Most often it is caused by a fall on the outstretched hand accompanied by twisting of the patient's body, forcibly pronating the forearm. Less often the cause is a violent blow to the forearm-as when a victim raises his arm to ward off an attack with a blunt instrument. In our age of increasing street violence this type of injury may increase.
There is only one exception to the rule that these fractures must always be treated surgically. In young children who suffer a greenstick fracture of the ulna, manipulation and the application of a well-padded plaster with the elbow fixed at about $80^{\circ}$ may be sufficient to cure the problem, but careful supervision and repeated $x$-ray examinations are essential. All other such fractures must be treated by open reduction. The ulnar shaft should be exposed and the fracture reduced and fixed in position by intramedullary nailing or plating. Once the length of the ulna is reconstituted manipulative reduction of the radial head may correct this part of the injury complex. A full plaster from metacarpal heads to the insertion of the deltoid muscle is essential to hold the elbow at a right-angle with the forearm supinated.

Reduction of the radial head by manipulation may not be possible because of the obstruction caused by the torn annular ligament. If this is the case the radial side of the elbow joint should be explored, the offending part of the ligament excised, and the head reduced under direct vision. Rarely, the radial head may need to be held in position by Kirschner wires, but reconstruction of the ligament is generally not necessary. The fracture usually heals in six to eight weeks.

The radial head should not be removed early in the management of this injury complex. Such ill-advised surgery may well produce traumatic ossification and may lead to a disruption of the distal radioulnar joint because of the proximal migration of the radius. Excision of the radial head may be necessary in adults if the radius has been left in the dislocated position or if the radial head has sustained a comminuted fracture, but only after the ulnar fracture has healed. In children the head is best left alone, no matter what its position, until growth has ceased. ${ }^{3}$ Late surgical reduction and reconstruction of the annular ligament is a difficult procedure, and the results are usually poor.

The catalogue of complications of the Monteggia fracture is completed by cross-union between the radius and ulna and non-union of the ulnar shaft-both uncommon. Fortunately for orthopaedic surgeons and patients alike, this unpleasant fracture-dislocation is a comparative rarity.

${ }^{1}$ Mullan GB, Franklin A, Thomas NP. Adult Monteggia lesion with ipsilateral wrist injuries. Injury $1981 ; 12: 413-6$.

2 Watson-Jones $\mathrm{R}$. Injuries of the forearm. In: Wilson JN, ed. Watsonfones fractures and joint injuries. Vol 2. 5th ed. Edinburgh: Churchill Livingstone, 1976:692-8.

${ }^{3}$ Sharrard WJW. Fractures of the forearm and hand. In: Sharrard WJW, ed. Paediatric orthopaedics and fractures. Vol 2. 2nd ed. Oxford: Blackwell Scientific Publications, 1979:1551-5.

\section{Evaluation of laboratory tests}

The mistaken belief that the NHS is "free" has lulled too many doctors and patients into equating "want" with "need," leading to continually increasing demand instead of the falling demand envisaged by Beveridge. Successive governments have recognised the problem and have responded by ever-tightening austerity and measures such as cash limits. The current emphasis is on seeking savings without detriment to standards of patient care, and the hospital sector has been singled out for the chief examination. In particular, there has been almost a crusade for cutting laboratory costs.

This crusade is based on the belief ${ }^{12}$ that the large range of easily performed and relatively cheap tests now available has 